\title{
QUEEN'S
UNIVERSITY
BELFAST
}

\section{What makes it so hard to look and to listen? Exploring the use of the Cognitive and Affective Supervisory Approach with children's social work managers}

Turney, D., \& Ruch, G. (2018). What makes it so hard to look and to listen? Exploring the use of the Cognitive and Affective Supervisory Approach with children's social work managers. Journal Of Social Work Practice, 32(2), 125-138. https://doi.org/10.1080/02650533.2018.1439460

\section{Published in:}

Journal Of Social Work Practice

\section{Document Version:}

Publisher's PDF, also known as Version of record

\section{Queen's University Belfast - Research Portal:}

Link to publication record in Queen's University Belfast Research Portal

\section{Publisher rights}

Copyright 2018 the authors.

This is an open access article published under a Creative Commons Attribution License (https://creativecommons.org/licenses/by/4.0/), which permits unrestricted use, distribution and reproduction in any medium, provided the author and source are cited.

\section{General rights}

Copyright for the publications made accessible via the Queen's University Belfast Research Portal is retained by the author(s) and / or other copyright owners and it is a condition of accessing these publications that users recognise and abide by the legal requirements associated with these rights.

Take down policy

The Research Portal is Queen's institutional repository that provides access to Queen's research output. Every effort has been made to ensure that content in the Research Portal does not infringe any person's rights, or applicable UK laws. If you discover content in the

Research Portal that you believe breaches copyright or violates any law, please contact openaccess@qub.ac.uk. 


\section{What makes it so hard to look and to listen? Exploring the use of the Cognitive and Affective Supervisory Approach with children's social work managers}

\section{Danielle Turney \& Gillian Ruch}

To cite this article: Danielle Turney \& Gillian Ruch (2018) What makes it so hard to look and to listen? Exploring the use of the Cognitive and Affective Supervisory Approach with children's social work managers, Journal of Social Work Practice, 32:2, 125-138, DOI: 10.1080/02650533.2018.1439460

To link to this article: https://doi.org/10.1080/02650533.2018.1439460
(c) 2018 The Author(s). Published by Informa UK Limited, trading as Taylor \& Francis Group.

曲 Published online: 02 May 2018.

Submit your article to this journal

Llll Article views: 170

View Crossmark data $\asymp$ 


\title{
What makes it so hard to look and to listen? Exploring the use of the Cognitive and Affective Supervisory Approach with children's social work managers
}

\author{
Danielle Turney ${ }^{\mathrm{a}}$ and Gillian Ruch ${ }^{\mathrm{b}}$

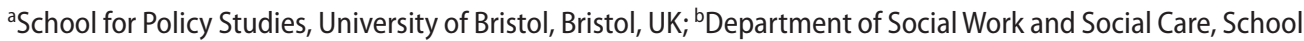 \\ of Education and Social Work, University of Sussex, Brighton, UK
}

\begin{abstract}
This paper reports on the findings of an ESRC-funded Knowledge Exchange project designed to explore the contribution of an innovative approach to supervision to social work practitioners' assessment and decision-making practices. The Cognitive and Affective Supervisory Approach (CASA) is informed by cognitive interviewing techniques originally designed to elicit best evidence from witnesses and victims of crime. Adapted here for use in childcare social work supervision contexts, this model is designed to enhance the quantity and quality of information available for decision-making. Facilitating the reporting of both 'event information' and 'emotion information', it allows a more detailed picture to emerge of events, as recalled by the individual involved, and the meaning they give to them. Practice supervisors from Children's Services in two local authorities undertook to introduce the CASA into supervision sessions and were supported in this through the provision of regular reflective group discussions. The project findings highlight the challenges for practitioners of 'detailed looking' and for supervisors of 'active listening'. The paper concludes by acknowledging that the CASA's successful contribution to decision-making is contingent on both the motivation and confidence of supervisors to develop their skills and an organisational commitment to, and resourcing of, reflective supervisory practices and spaces.
\end{abstract}

\section{KEYWORDS}

Supervision; Cognitive Interviewing; decisionmaking; emotion; information; active listening

\section{Introduction}

Concerns about the quality of social work assessment and decision-making practices are long-standing and familiar, becoming heightened in the face of high-profile public inquiries or serious case reviews into the death of or harm to a child (Brandon et al., 2008; Munro, 2011; Turney, Platt, Selwyn, \& Farmer, 2012). The research reported here that utilises the Cognitive and Affective Supervisory Approach (CASA) outlined below, was designed and conducted precisely to respond to these concerns by exploring how the emotional dimensions of everyday social work practice can be brought more intentionally and explicitly into assessment and decision-making processes. Our focus is on supervision, reflecting its 
role as a key site for decision-making and the need, therefore, for social work supervisors to have appropriate skills in supporting this in practice (Department for Education, 2015). Supervision has been consistently identified as a cornerstone of good practice (Beddoe \& Davys, 2016) but until recently, the detail of what happens, how and when to make it so has been somewhat under-researched (Carpenter, Webb, \& Bostock, 2013), although work by Beddoe and Davys (2010, 2016) in New Zealand and Wilkins (Wilkins, 2017a, 2017b, Wilkins, Forrester, \& Grant, 2017) in England in particular has added important insights about supervision 'in action'. The present discussion makes an original, research informed contribution to this developing knowledge base.

The CASA is an innovative practice-based method designed to try and enhance the quantity and quality of information available for decision-making by focusing on both the cognitive and affective dimensions of practitioners' experiences (Turney \& Ruch, 2016). It assumes that recognition of the emotional content of practice is key to safe and effective decision-making but that supervision has not always provided the necessary space for this kind of reflection and analysis (Beddoe, 2010; Gibbs, 2001; Ingram, 2013). CASA draws on Cognitive Interviewing (CI) techniques (originally designed for use in forensic settings to elicit best evidence from witnesses and victims of crime), and has adapted them for use in a new professional context to help practitioners provide fuller accounts of events they encounter in everyday social work practice - accounts that potentially report both 'event information' and 'emotion information' (awareness of mood, changes of affect, emotional responses).

As indicated, our interest is particularly in the role that 'emotion information' (Turney \& Ruch, 2016) plays in supervision discussion and decision-making, particularly in a context that has seen increased bureaucratisation and proceduralisation of practice, a proliferation of performance indicators and audits and a move 'from the relational to the informational' (Parton, 2009). Alongside these developments in the broader environment of practice, more procedurally driven 'case management' supervision has taken hold, typically at the expense of more reflective modes of supervision. It is widely acknowledged that reflective practice requires the integration of thinking, doing and feeling (Ruch, 2002) but recent research into child care practices more generally (Gibson, 2016; Lees, 2017; Thompson, 2013) and supervision practices more specifically (Ingram, 2013) highlight the complexities embedded in this professional domain and the central role played by emotions. Concerns expressed in The Munro Review reports (2011) about overly proceduralised practice and its commitment to shifting from a 'case management' to a more reflective and 'emotionally inclusive' (Ingram, 2013, p. 6) mode of supervision, for example, have not been straightforwardly achieved. What these studies highlight, in particular, is the unpredictable, non-linear and irrational (in the best sense of the word) ways in which practice is encountered, experienced, understood and subsequently managed.

Some of the (often unintended) consequences of these developments and their impacts on day-to-day practice with children and families have been highlighted, with findings from a range of studies pointing to the fragmentation and sanitisation of practice (Broadhurst, Hall, Wastell, White, \& Pithouse, 2010; Cooper \& Lees, 2015; Hall, Parton, \& White, 2010; Peckover, White, \& Hall, 2008; Shaw et al., 2009; Winter et al., 2017), the way that 'the balance between following rules and exercising professional expertise has become skewed' (Munro, 2011, p. 87), and a concern that supervision has been colonised by 'new public management' (Ingram, 2013; Lees, Meyer, \& Rafferty, 2013; Ruch, 2011). 
Against this rather bleak backdrop it is clear that there is a pressing need for a new approach to supervision, but if the integrated cognitive-affective approach we are advocating for is to have any chance of gaining purchase, it is vital we do not underestimate the scale and nature of the obstacles in its way. And more recently, the entrenched challenges that have already been identified have been compounded by the continuing impacts of 'austerity politics' on already vulnerable families, cuts to services and increased pressure on professionals to 'do more with less'. In such circumstances, the risk of a form of relational austerity (Hingley-Jones \& Ruch, 2016) taking root is heightened and the relevance and meaning of emotional engagement and responses may become even more invisible.

\section{The study}

The CASA research project was designed as a small scale, exploratory and collaborative knowledge exchange between the participating social workers and their agencies, and the academic team. Whilst trying to achieve co-production presented a number of challenges (mainly related to the work-based demands that participants were managing), this approach nonetheless offered a creative and constructive way both to generate practice-focused research data and to provide opportunities for continuing professional development. As the project involved developing and trialling a new method, the researchers aimed to engage the participants actively in creating both the 'product' (CASA) and the knowledge 'outputs' that might emerge from its use in practice. Locating ourselves within a 'practice-near' (Froggett \& Briggs, 2012) mode of inquiry and undertaking research in practice allowed us to:

utilise practice approaches and interventions as research methods. This approach is characterised by a greater sense of immediacy and refers to the integration and application of new practice knowledge within the immediate research context and directly in the practice domain.

(Quote from Ruch, cited in Winter et al., 2015)

As with all research, unexpected dynamics and consequences arise and 'practice near' research is no exception with, in this instance, the very challenges the supervisors encountered in their day-to-day practice, discussed below, being mirrored in the research process.

The framework, the CASA, was developed from Geiselman and Fisher's CI model (Fisher \& Geiselman, 1992; Geiselman, Fisher, MacKinnon, \& Holland, 1986) and used the four 'mnemonics' they devised to aid information retrieval:

- Mentally re-instating the environmental and personal context;

- Reporting everything, even partial information, without editing;

- Recounting the events in different order; and

- Reporting the events from different perspectives (Geiselman et al., 1986).

Using Milne's (2004) guide to CI as the basis for our work, the researchers in consultation with two local authority social work supervisors, adapted the CI for use in social work supervision, the aim being to develop a protocol that could be used to try and enhance the quality of the information that underpins social work assessment and decision-making (see also Authors' own, 2016 for further discussion). This involved changing some of the language used, to reflect the move from the forensic/police interview context to that of social work supervision (e.g. removing references to 'the offence', referring to the 'supervisor'/'supervisee' rather than the 'interviewer'/'Interviewee'). Our approach also involved making space in the 'CASA conversation' for the explicit acknowledgement of the supervisee's cognitive 
and affective responses, in order to promote effective thinking in and about practice. Our intention was to offer a space where the thoughts and feelings about a case could be given equal attention, 'event information' and 'emotion information' could be brought together and the impact of attacks on 'linking' (Bion, 1962) could be minimised. Conceptualising the supervisory space in this way enables it to be understood as a place of containment with the supervisor acting as the container. In turn, we intended that the reflective group discussion forums would provide an emotionally containing space for the supervisors that would promote learning and professional development.

The project involved introducing a new framework for supervisory discussion into the day-to-day practice of social work supervisors and prior to recruiting participants ethical approval was obtained from the lead author's University's ethics committee and the participating local authorities. A call for participants via the Principal Social Workers (Children and Families) in two neighbouring local authorities led to expressions of interest from 14 supervisors. A meeting was arranged where the CASA protocol was introduced to the potential participants who were then supported to familiarise themselves with its use. From there, the group was split into two (for the geographical convenience of the group members) and these two smaller groups of practice supervisors were invited to attend monthly local reflective discussion sessions. The choice about which of their supervisees to include was left to the discretion of the participating supervisors. We [the researchers] indicated that we would be interested to learn how they decided who to involve, as well as the outcomes in terms of their use of and response to the CASA framework in supervision. Supervisors identified a range of opportunities and contexts for trying out the CASA framework, related to their own team setting and group of supervisees.

A core group of supervisors engaged consistently with the project and made effective use of the reflective discussion groups to explore their experiences; however overall, the study generated fewer examples of the use of the CASA than had originally been hoped. The original intention was that each supervisor would use the approach with up to three of their supervisees on different occasions over an agreed period of time (5-6 months), but this proved to be overly optimistic. In the event, seven supervisors did manage to introduce CASA into their supervision sessions, and used it on more than one occasion, but not all used it both with more than one supervisee and the same supervisee in different supervision sessions. Twelve individual and five group supervision sessions were recorded plus two 'CASA conversations' took place that were not recorded, (but were discussed by the supervisors in the reflective group). The reflective groups worked to a broadly similar agenda for each meeting, with one member in each of the groups presenting an experience of using the CASA; the person presenting was invited to talk about the supervision example (without interruption from the rest of the group), highlighting whatever seemed pertinent to them; they then withdrew from the group and listened as the other participants reflected on what they had heard. Underpinning this reflective discussion model (Ruch, 2007) is the intention that taking the presenter out of the group avoids the group falling into a default 'problem solving interrogation' approach, a phenomenon all too common in such groups (and also in supervision sessions, we would suggest). Rather, by creating a reflective space participants are invited to engage more deeply and inclusively with the case material presented: more deeply in terms of their affective as well as their cognitive responses and more inclusively in terms of their curiosity, 'noticing what they notice' and noticing too what might be getting overlooked or whose voices might be marginalised. Broadly based on psychoanalytic and 
systemic understandings of how people behave, they invite individuals to 'get beneath the surface' and think 'around the edges'.

Our focus in this paper is on the understanding we gained from analysing the transcripts of both the monthly reflective group discussion meetings and the individual CASA supervision sessions, with particular reference to the way 'emotion information' was introduced or included by the supervisee, how this information was managed or used in the particular supervision session and/or the reflective group discussion, and the participants' (supervisors and supervisees) reflections on how/whether it contributed to subsequent decision-making. As noted, discussion of the findings also involves reference to the research process itself, as this provided useful insights into the current 'real world' context within which supervision takes place and how it affects supervisory practice.

We used a thematic approach (Braun \& Clarke, 2006; Clarke \& Braun, 2013) to analysis and have brought a psychosocial sensibility to bear in thematising the data, in keeping with our interest in the expression and meaning of emotion in practice contexts. As Sclater, Jones, Price, and Yates (2009, p. 1) observe:

emotions exist partly in the body, but they are also in our minds, in our language and in the cultures that surround us. They can be understood as a crucial bridge between the individual and social, and are quintessentially psychosocial phenomena.

\section{Findings}

We discuss some key findings from the project, firstly identifying a number of significant process issues - related to getting started and learning how to 'do it' - that we became aware of in the course of the reflective discussion groups and which showed that there were significant concerns about managing the task of when and how to introduce the CASA into supervision. We then move on to look at what we learned about the usefulness of CASA in terms of facilitating active listening and eliciting both event and emotion information and how this information was used. The surprising nature of some of the findings, not least the process orientated ones, led us to reflect on the potential parallels between these dynamics and those that occur in everyday supervision practice, which we explore further in the discussion section below.

\section{When to do it: getting started}

Some common themes began to emerge quite early on in the reflective discussions: the first was that a number of supervisors struggled to get started, despite having had a chance to explore and experiment with the CASA in practice sessions. Challenges around actually taking the step of just trying to introduce the CASA framework into a supervision session became a recurrent theme for discussion in the monthly supervisor meetings. It was acknowledged that it is always tricky to work out how to get started with a new approach but we [the researchers] emphasised that we saw it as a learning process, so we would all gain something from seeing how/whether the CASA approach works for different people in different contexts. We therefore urged supervisors not to wait for the 'perfect moment' but just to have a go and see what happened.

Despite the encouragement we offered, and clear preparatory work, how and when to 'use the CASA' still proved challenging with most of the supervisors expressing their confusion 
as to when it was most appropriate to use it. Early discussions focussed on which sort of work the approach was most suited to with initial conversations aligning the approach with the fast-paced work of duty and assessment and a sense that crisis-led, incident focussed work was more suitable for the practitioners to present in a supervision session using the CASA. For Sally, a Looked After Children's (LAC) team manager, this was certainly the case.

Sally: Well I think, what is in my head quite firmly, is the sense I have that it could be a really, really useful tool in safeguarding primarily. That's my thinking, that you've come back from a visit, the first visit in a section 47 investigation, for example, and you want to feed back what that was about.

That said, Sally, to her own surprise, then went on to counter this view when she tried introducing the CASA into supervision sessions with two of her LAC team members:

Sally: And interestingly, they both said, each of the social workers said before they started, 'oh I don't think I'll be able to do this, you know, I'll only manage five minutes'. And they both talked consistently for about 35, $40 \mathrm{~min}$, and I said to them both afterwards, because they both had the clock behind them, I said, you won't believe how long you've been speaking for, because ... And then each time they'd say, 'I don't think I can remember any more'. And then they'd start talking. (Reflective Group B2)

We were equally surprised to discover how, despite the voiced reservations about using the CASA, some specific and unexpected adaptations were unilaterally introduced. In one setting it was superimposed onto regular group supervision sessions, with the team manager, Lee, using the approach with one practitioner, whilst the remaining team members observed. In another instance Paul introduced it 'on the hoof' with a practitioner who had had a challenging encounter with a mother and appeared to be wanting to escalate the situation to a Child Protection concern. Rather than follow the model more systematically Paul chose to use one of the mnemonic elements that involved reporting from a different perspective with the worker. Following the CASA-informed intervention the discussion took a different direction and the worker, according to Paul, appeared to gain a different perspective on the nature of her interaction with the parent and her subsequent response:

Paul: So for example, that case yesterday I could have very easily been agreeing to have a strategy discussion and asking for child protection conference for that family who doesn't need it. So already, if it [introducing CASA into supervision] comes to nothing, for one family maybe something is a little different.

Researcher: Yes, and your conversation with that social worker was different in terms of what you did and what she did.

Paul: Yes, and while you're saying 'it's different for that one family; it could have had a different outcome for that family', it could have a different outcome for lots of families because it may ... it's going to influence what that social worker does in future and how they respond in future. (Reflective Group B1)

The unexpected wider implications arising from this application of the CASA suggests that adopting a versatile approach to how it is implemented is not inappropriate, and may generate valuable outcomes.

\section{How to do it? Practically adopting the approach}

As part of the research process, supervisors were asked to record the supervision sessions when they used the CASA. Early on a surprising level of concern emerged in relation to the 
use of audio recorders to 'capture' the session. Over and above the ordinary techno-phobic responses that recording devices can elicit, supervisors reported interesting experiences in terms of how using an audio recorder impacted on their capacity to listen and to remember. For Carol the recorder was almost unmentionable, and she resorted to referring to it as 'that' (with gestures). Even more powerfully for Carol the presence of the recorder proved to be such an unsettling experience that the first time she used the CASA in supervision with the recorder, she could not subsequently remember any of the details of what had been discussed with the practitioner, attributing this to the recorder being on. Discussing this experience in the reflective group, Carol acknowledged her ambivalence about being recorded. This led the group to wonder whether knowing she was being recorded might have allowed Carol to, in some sense, 'switch off' from what she was hearing or whether her ambivalence about being recorded simply blocked her capacity to recall the conversation. The strength of the resistance to recording seemed to speak to the widely acknowledged 'hidden' nature of the supervision process and experience (Carpenter et al. 2013) and suggested a degree of anxiety about being 'exposed' as a result of having a supervision session 'on record' in this way.

In introducing the CASA to supervision sessions, we envisaged it would offer a new way of eliciting information which would then be fed into the analysis, assessment and decision-making phases of supervision. The idea behind the CASA approach is that once a body of evidence is gathered then the analysis phase of the supervision session can take place that will inform the professional judgements reached and subsequent decision-making. We therefore asked participants to record the whole supervision session where the CASA was being used, as we were interested not just in how they went about the information-gathering stage but also how/whether the information presented then informed the subsequent supervision discussion and any decisions or further actions. In essence, we saw the CASA conversation being an integral part of the usual supervision processes and not as a standalone element. This expectation, however, appeared to be more problematic than we had anticipated and supervisors frequently failed to continue the recording into the latter part of the session, although (as indicated in the reflective group meetings and the feedback from practitioners) they clearly did continue the supervision discussion. It presented us with a conundrum about how we might make sense of this behaviour, discussed further below.

\section{Active listening and not knowing}

A feature of the reflective case discussion conversations and the feedback from supervisees was the counter-intuitive nature of the CASA in the current climate, even for practitioners/ supervisors who considered themselves to be reflective. A recurrent theme, was the contrast of the CASA with 'business as usual', case management orientated supervision, which precludes attention to detail and more open-ended conversations. Here, Researcher 1 has just commented on the opportunity afforded by the CASA to hear a full account from a supervisee, rather than just what they have decided are the 'key points':

Faye: But you're right, there's something about what supervision has become that inhibits that, isn't there? Because exactly that; so all day I have workers coming at me and we do, we sit and they spew details then. They'll tell you what it smelt like, what it felt, where the cobwebs were; detail after detail after detail. When you go into supervision ...

Researcher 2: It's all cleaned up. 
Faye: Because what they think they're there to tell you is that they've achieved their tasks and they know where they're going with the case. And there's something about supervision that's ... And they're there, you know, with 27 children to get through so they ... And they're not in that moment of having come out of that visit and so they're just like, onto the next one, because they haven't got an hour to spend on each child. (Reflective group B1)

A significant, and unexpected, finding of the research was the scale of the challenge supervisors encountered in adopting the 'CASA mindset', most notably learning how to actively listen, to 'not know' and to resist interrupting in order to avoid premature problem solving. The approach invites supervisors to help supervisees to 'stay in the moment' with the aim of acquiring a detailed recall of the event and gathering a solid body of 'evidence'/ detailed information. The reflective discussion groups then provided a space for the supervisors to think about what it felt like to take up an 'active listening' position - and, as it turned out, to discover how unfamiliar it could feel. Supervisors very quickly acknowledged the challenge they experienced in being asked to adopt the active listener role, with Lee (Reflective Group A2) capturing this succinctly in a slightly flippant but nonetheless telling comment, 'I've solved the problem before I even know what the problem is.' This position was echoed by Sally:

Sally: I found it really hard to keep my mouth shut, that was really hard. And I did talk a lot. And I think I know that I go a bit into, I want to fix it, you know, I want ... I do kind of ... I know from being observed [...] in previous supervision trainings that I'm inclined to, 'let me help you find the problem', let me, you know, or, 'let me facilitate you finding the problem.' (Reflective Group B2)

Other remarks included Alice referring to needing to 'sit on her hands' and Naomi's acknowledgement of the challenge she faced in 'keeping quiet and zipping it', and recognition of a problem-solving mindset dominating her responses:

Naomi: 'You know, because there's that sense that you do want to sort of, help people think it through and, you know, just step in and say 'oh-oh.' (Reflective Group B2)

The invitation to simply listen and not to interrupt seemed to trigger all sorts of questions for the supervisors - how do I do this? What is it achieving? - leaving them appearing, at times, to feel that they were not 'doing' anything or to be genuinely unsure whether they were doing enough by 'just' listening. For Paul, the fear of not asking questions was that he would 'drift off' and so by asking questions he would stay engaged in the conversation, whilst this prompted Judy to reflect on what practitioners might expect of their supervisor and how this could be shifted:

Judy: ... their [supervisees'] expectation ... that we go into supervision and our staff think, I'll load it all down, they're going to tell me the answer.

Researcher 1: They can sort it out, yes ... ?

Judy: I think by saying right at the beginning, we're not going to have an answer, you are ... [...] well, it changes the expectation doesn't it of ... you know, they can just dump it all on you ... (Reflective Group B1)

In referring to supervisees' expectations Judy acknowledged a crucial aspect of the CASA process - how the eliciting of information is understood and operationalised. 


\section{Eliciting emotion information}

The supervision accounts we gathered showed that the content of the CASA conversations was frequently rich and expansive and this raised many questions too which were explored in the groups. There was some discussion about the risks of 'opening up' an emotionally sensitive issue or exploring an emotionally challenging or distressing situation, with supervisors questioning how open they felt they were (or could be) to emotion information: will we be able to manage what we hear? Will we be able to stop it appropriately? For Paul, from the supervisor perspective, the 'reward' of using the CASA was swift. In using one element of it with a practitioner he was quickly able to gain a different perspective that did not result in the escalated intervention that the practitioner was initially proposing. For Sally, what caught her attention was the level of detail recalled by the two practitioners concerned and its unexpected impact on her confidence (or not) in the practitioners' skills and knowledge and her own perspective on a case:

Sally: And it was amazing what they remembered. It was amazing what they picked up. And it was really ... And I praise them both, I think, I hope, because they obviously really knew their children. They really knew the children and they really got into the child's experience. And that was really revealing. I wasn't surprised, obviously, you know. I knew that would be the case and it ... But yes, it was ... And it gave them the space to, you know, kind of an affirmation of, 'you're valued, because I'm sitting here and I'm giving my time to listen to you'. And all of that, although it's just a snapshot in an ongoing relationship, is really important: 'What you're doing is really important'. So I suppose that's the other value of it [CASA], isn't it, that now I've ... My shift ... My thinking has shifted [...] now, to seeing it not at all what I thought it was - the tool for that, but I can see how valuable it is in what we do. (Reflective Group B2)

Feedback from practitioners who had discussed their work using the CASA emphasised the impact and usefulness of having time to just talk, with the pace of the CASA session highlighted as being conspicuously different from 'regular' supervision: one practitioner (social worker 3) noted the slower pace of the session, and took the point of the approach to be 'not racing to find an answer ... or to fix things', for another (social worker 4) there was appreciation of the opportunity the CASA created to think in-depth about a case, whilst another practitioner (social worker 2) commented: it felt more important, more intense ... slower but more intense focus on one thing'.

From the practitioners' point of view, the capacity of this approach to generate unexpected responses was important. For some, the CASA supervisions had made them aware of new information that had changed, to some degree, how they thought about the case they had brought for consideration. One practitioner (social worker 1) talked about the impact of 'taking away all the process stuff, and just thinking' about the case she'd brought, and how she found it interesting to consider the 'memory recall stuff' and what you retain. She then went on to note the surprise she had felt on realising that she had initially forgotten to mention - or had pushed away - what she thought was actually the most important thing about the meeting she was recounting. She commented on "how I'd forgotten the most crucial bit because my brain had gone "I just want to forget about this" .... Whilst practitioners responded in different ways to the CASA experience, a common theme in their responses was how the use of the CASA drew out particular changes in the practitioners' understanding that had come about in the course of the CASA discussion. These new insights then 
became material that was factored into their (and their supervisor's) thinking about further responses to the case in hand.

\section{Discussion}

We have given a certain amount of space here to reflecting on our journey through this research project, as we believe it speaks powerfully to how supervision is currently understood, valued and experienced. There is disjuncture between, on the one hand, the importance ascribed to it by organisations, managers and practitioners and on the other hand, the space/time they can make to think about it beyond simply delivering/receiving it. This was demonstrated time and again in the way that introducing the CASA seemed to be such a difficult task/process for supervisors to engage in. Despite having had a fair amount of preparatory input, it seemed that some aspects were simply not grasped and several factors seemed to 'get in the way': e.g. recording (when/whether/how to record), how/when to use CASA (what kinds of situation is it suitable for; does it work best if used for 'spontaneous' discussion). It seemed to us that there was a strong underlying anxiety about getting it 'wrong', which impacted on how supervisors felt about their supervisory practice being 'made public'. Having noted this, one of the roles of the reflective group facilitation was to model the position of curiosity that is intrinsic to the CASA and encourage the participants to reflect on these dynamics - did they feel there was a 'right-wrong'; why did recordings get 'cut short'; why was the supervisors' curiosity/ logical thinking interrupted? Discussion in the groups enabled them to explore their own responses, express their curiosity about what might be happening and reflect on the impact of not being completely in control of the supervision session.

The findings suggest that the capacity of the model to disrupt conventional linear patterns of thinking allows for emotional dimensions of practice to be more readily accessed and drawn on to accommodate more expansive and in-depth understanding, but this cannot be relied upon as a foregone conclusion from using the CASA. As indicated in the previous section, one issue that came to light was the supervisors' response to including the 'postCASA' part of their supervisory discussion in the recording. Despite frequent reminders, some did not appear (at least initially) to see a connection between the CASA element and the subsequent supervision discussion. Drawing on Bion's (1959) work on attacks on linking, it is possible to see that this break between the two parts of the session could be seen to mirror the potential for disconnect between thinking and feeling that can pervade practice. It perhaps also mirrors the separation that can arise if line management and clinical supervision are disconnected. It is a significant challenge to hold thinking and feeling, process and task together, yet it is precisely this idea of a non-binary, integrated depressive position in supervision that the CASA seeks to offer but which is so difficult for supervisors to enact.

So what does the binary position defend against? Some practitioners seemed to find recalling both event and emotion information quite challenging and tended to go into more assessment/analytic talk as opposed to simply description. Helping practitioners understand the value of detailed recall as a conduit to both accurate event information and richer emotion information was clearly something the supervisors had to focus on. It is not difficult, however, to see why practitioners might wish to avoid attending to detail. As one practitioner, who had completed an infant observation exercise, commented in supervision with Sally, if time is permitted for practitioners to really observe, then there is the risk that they 
might discover things they do not wish to see. Such an understanding echoes the references to 'turning a blind eye' that have been associated with childcare tragedies such as Victoria Climbié (Rustin, 2005). If practitioners do see what is before them there maybe a significant emotional cost. That said, 'not seeing' runs the risk of even greater costs.

An equally significant hurdle to be overcome if the full potential of the CASA is to be realised is how difficult supervisors found it to utilise 'active listening', as opposed to 'problem solving' skills, and their limited ability initially to see the potential of 'active listening'. The imperative in practice for fast turn around and through-putting of cases in order to meet performance indicators and audit requirements runs counter to the emphasis in the CASA of slowing down and attending to detail. This tension in practice highlights the difficulty in preserving reflective spaces for both practitioners and supervisors. Supervisors using the CASA, therefore, had to consciously and intentionally adopt a counter-cultural mindset, confident that it could enhance decision-making and, therefore, produce better outcomes and efficiencies.

The risk associated with these two practitioner and supervisor-focused obstacles is of a premature rush to the analysis and assessment phases of decision-making without sufficiently detailed engagement with the full facts or emotionally informed perspectives. Addressing both constraining forces is essential if the full potential of the CASA is to be realised and the project findings suggest more work is required that configures supervision as a space for managing one's own and others' emotions, a space which offers supervisees 'Understanding, acknowledgement, recognition, validation, affirmation and confirmation ...' (Smith, 2000, p. 17).

Viewing the data and its findings in the context of the triadic integration of thinking, feeling and doing explored by Ruch (2002), sheds some interesting light on supervision processes. The way both supervisors and supervisees in the project discussed current supervisory practice often emphasised 'doing' at the expense, it seemed, of leaving space for thinking or feeling. The supervisors in our study were very aware of their wish to jump in and problem solve and, in some cases, to 'rescue' practitioners, sometimes at the expense of actually being able to properly listen to what the supervisee wanted to tell them about an experience. Whilst the supervisors were clearly personally committed to the notion of reflection, the day-to-day demands of many settings and the inevitable pressures of time scales and other key performance indicators meant that ensuring the 'right' things (i.e. those that met externally specified targets) were being done took precedence over making sure that the right kind of thinking was being supported. Adopting the CASA in at least some sessions allowed the dynamics between the different elements to shift and for new positions to be adopted. Whilst in its original form, the emphasis in the cognitive interview process was on the quality of the information/evidence our experience suggests that this is inextricably linked to the quality of active listening.

Thus, a fascinating discovery arising from using the CASA is the significance of an unrecognised fourth dimension - listening - in the traditional triadic reflective cycle of thinking, feeling and doing. The CASA creates an opportunity for more consideration to be given to this dimension of the supervisory process, enabling supervisors to be confident that 'active listening' can be in and of itself informative and constructive. Simultaneously supervisees need to trust that in daring to detail their experiences new insights can emerge simply through the process of telling and the emotional availability and active listening of their supervisor. Our research suggests the CASA can provide a framework for structuring 
these experiences but given that exercising listening skills and emotional intelligence are currently counter-cultural professional ways of behaving, it is vital that time and professional development resources are invested in order for CASA and equivalent approaches to be effectively embedded within organisational cultures.

\section{Conclusions}

The study reported introduced an innovative practice approach for use in children \& families social work supervision - the CASA. The findings make a distinctive contribution to the understanding of the role and practices of supervision in everyday social work settings, and to the development of the evidence base in relation to reflective supervision. We are of course aware of the modest scale of the study, so a focused, larger scale programme of work would be needed to formally evaluate the efficacy (or not) of the model more generally. However, feedback from participants, both supervisors and supervisees, indicated that the CASA has practical utility and can be used to support supervision discussion in a range of practice situations and encounters, allowing for a kind of discussion that was different from 'business as usual' - the latter defined as more focused on case management and direction, and problem solving. Utilising the CASA gave the practitioner time and space to explore a particular element of their work in more detail and allowed new insights to emerge that informed future case planning. As the research team, we observed, however, that a tension remained between participants' expressed interest in and engagement with the CASA 'in principle' and the hesitancy encountered in trialling its use in practice. This was a recurrent topic for consideration throughout the project and suggests that adopting an approach of this kind is not just a matter of individuals taking up a new technique; rather, it appears that embedding the CASA requires both individual commitment and a level of organisational re-thinking to promote a cultural shift in perception about the role and purpose of supervision.

\section{Disclosure statement}

No potential conflict of interest was reported by the authors.

\section{Funding}

This research study discussed here was funded by the Economic and Social Research Council [grant number ES/M006220/1]. The application of a cognitive and affective interviewing model in social work supervision.

\section{Notes on contributors}

Danielle Turney is a senior lecturer in Social Work and head of the Children and Families Research Centre in the School for Policy Studies, at the University of Bristol. Her research interests focus on child neglect; relationship-based practice; and the role of analysis and professional judgement in social work assessment and decision-making (email: danielle.turney@bristol.ac.uk).

Gillian Ruch is a professor of Social Work at the University of Sussex, where she teaches and researches in the areas of child care social work, relationship-based and reflective practice (email: g.ruch@ sussex.ac.uk). 


\section{References}

Beddoe, L. (2010). Surveillance or reflection: Professional Supervision in 'the Risk Society'. British Journal of Social Work, 40(4), 1279-1296.

Beddoe, L., \& Davys, A. (2010). Best practice in professional supervision: A guide for the helping professions'. London: Jessica Kingsley.

Beddoe, L., \& Davys, A. (2016). Challenges in professional supervision: Current themes and models for practice. London: Jessica Kingsley.

Bion, W. (1959). Attacks on linking. International Journal of Psycho-Analysis, 40(5-6), 308.

Bion, W. (1962). Learning from Experience. London: Heinemann.

Brandon, M., Belderson, P., Warren, C., Gardner, R., Howe, D., Dodsworth, J., \& Black, J. (2008). Analysing child deaths through abuse and neglect: What can we learn?A Biennial analysis of serious case reviews 2003-2005, research report DCSF-RR023. London: Department for Children, Schools and Families (DCSF).

Braun, V., \& Clarke, V. (2006). Using thematic analysis in psychology. Qualitative Research in Psychology, 3(2), 77-101.

Broadhurst, K., Hall, C., Wastell, D., White, S., \& Pithouse, A. (2010). Risk, instrumentalism and the humane project in social work: Identifying the informal logics of risk management in children's statutory services. British Journal of Social Work, 40, 352-370.

Carpenter, J., Webb, C. M., \& Bostock, L. (2013). The surprisingly weak evidence base for supervision: Findings from a systematic review of research in child welfare practice (2000-2012). Children and Youth Services Review, 35(11), 1843-1853.

Clarke, V., \& Braun, V. (2013). Teaching thematic analysis: Overcoming challenges and developing strategies for effective learning. The Psychologist, 26(2), 120-123.

Cooper, A., \& Lees, A. (2015). Spotlit: Defences against anxiety in contemporary human service organisations. In D. Armstrong \& M. Rustin (Eds.), Social defences against anxiety: Explorations in a paradigm (pp. 239-255). London: Karnac.

Department for Education. (2015). Knowledge and skills statements for practice leaders and practice supervisors. Retrieved from https://www.gov.uk/government/uploads/system/uploads/attachment data/file/478111/Knowledge_and_skills_statements_for_practice_leaders_and_practice_ supervisors.pdf

Fisher, R. P., \& Geiselman, R. E. (1992). Memory enhancing techniques for investigative interviewing: The cognitive interview. Springfield, IL: Charles C Thomas Publisher.

Froggett, L., \& Briggs, S. (2012). Practice-near and practice-distant methods in human services research. Journal of Research Practice, 8(2), 9.

Geiselman, R. E., Fisher, R. P., MacKinnon, D. P., \& Holland, H. L. (1986). Enhancement of eyewitness memory with the cognitive interview. The American Journal of Psychology, 99(3), 385-401.

Gibbs, J. A. (2001). Maintaining front-line workers in child protection: A case for refocusing supervision. Child Abuse Review, 10, 323-335.

Gibson, M. (2016). Constructing pride, shame, and humiliation as a mechanism of control: A case study of an English local authority child protection service. Children and Youth Services Review, $70,120-128$.

Hall, C., Parton, N., \& White, S. (2010). Child-Centric Information and Communication Technology (ICT) and the fragmentation of child welfare practice in England. Journal of Social Policy, 39(03), 393-413.

Hingley-Jones, H., \& Ruch, G. (2016). Stumbling through? Relationship-based social work practice in austere times Journal of Social Work Practice, 30(3), 235-248.

Ingram, R. (2013). Emotions, social work practice and supervision: An uneasy alliance? Journal of Social Work Practice, 27(1), 5-19.

Lees, A. (2017). Facts with feelings - social workers' experiences of sharing information across team and agency borders to safeguard children. Child and Family Social Work, 22, 892-903.

Lees, A., Meyer, E., \& Rafferty, J. (2013). From Menzies Lyth to Munro: the problem of managerialism. British Journal of Social Work, 43(3), 542-558.

Milne, R. (2004). The cognitive interview: A step-by-step guide. Unpublished manuscript. 
Munro, E. R. (2011). Munro review of child protection: A child centred system. London: The Stationery Office.

Parton, N. (2009). Challenges to practice and knowledge in child welfare social work: From the 'social' to the 'informational'? Children and Youth Services Review, 31(7), 715-721.

Peckover, S., White, S., \& Hall, C. (2008). Making and managing electronic children: E assessment in child welfare. Information, Communication and Society, 11(3), 275-294.

Ruch, G. (2002). From triangle to spiral: Reflective practice in social work education, practice and research. Social Work Education, 21(2), 199-216.

Ruch, G. (2007). 'Thoughtful' practice: Child care social work and the role of case discussion. Child and Family Social Work, 12, 370-379.

Ruch, G. (2011). Where have all the feelings gone? Developing reflective relationship-based management in child-care social work. British Journal of Social Work, 42(7), 1315-1332.

Rustin, M. (2005). Conceptual analysis of critical moments in Victoria Climbiés life. Child and Family Social Work, 10, 11-19.

Sclater, S. D., Jones, D., Price, H., \& Yates, C. (Eds.). (2009). Emotion: New psychosocial perspectives. Basingstoke: Palgrave Macmillan.

Shaw, I., Bell, M., Sinclair, I., Sloper, P., Mitchell, W., Dyson, P., ... Rafferty, J. (2009). An exemplary scheme? An evaluation of the integrated children's system. British Journal of Social Work, 39(4), 613-626.

Smith, M. (2000). Supervision of fear in social work. A re-evaluation of reassurance. Journal of Social Work Practice, 14(1), 17-26.

Thompson, K. (2013). Multi-agency information practices in children's services: The metaphorical 'jigsaw' and professionals quest for a 'full' picture. Child \& Family Social Work, 18(2), 189-197.

Turney, D., Platt, D., Selwyn, J., \& Farmer, E. (2012). Improving child and family assessments: Turning research into practice. London: Jessica Kingsley.

Turney, D., \& Ruch, G. (2016). Thinking about thinking after Munro: The contribution of cognitive interviewing to child-care social work supervision and decision-making practices. British Journal of Social Work, 46(3), 669-685.

Wilkins, D. (2017a). How is supervision recorded in child and family social work? An analysis of 244 written records of formal supervision. Child \& Family Social Work, 22(3), 1130-1140.

Wilkins, D. (2017b). Does reflective supervision have a future in English local authority child and family social work? Journal of Children's Services, 12(2/3), 164-173.

Wilkins, D., Forrester, D., \& Grant, L. (2017). What happens in child and family social work supervision? Child \& Family Social Work, 22(2), 942-951.

Winter, K., Cree, V. E., Ruch, G., Hallett, S., Hadfield, M., \& Morrison, F. (2017). Effective communication between social workers and children and young people'. British Journal of Social Work, 47(5), 1427-1444.

Winter, K., Hallett, S., Morrison, F., Cree, V., Ruch, G., Hatfield, M., \& Holland, S. (2015). Practice-near research: Exploring insights from different degrees of closeness. Edinburgh: BASPCAN Congress. 